\title{
A Maternidade na História e a História dos Cuidados Maternos
}

The maternity in history and the history of the maternal care

\section{Solange Maria Sobottka Rolim de Moura \\ Psicóloga, Mestre em Psicologia pela Universidade Estadual Paulista - UNESP - Campus de Assis}

Maria de Fátima Araújo

\section{Psicóloga. Doutora em Psicologia pela Universidade de São Paulo. Docente da Universidade Estadual Paulista - UNESP - Campus de} Assis

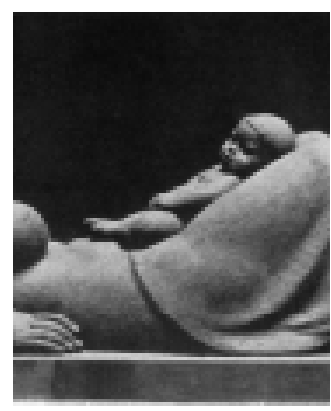

Resumo: Neste artigo, discute-se a naturalização de conceitos e práticas relacionadas à maternidade e aos cuidados maternos, associando-se sua construção social às modificações pelas quais a família tem passado, na Europa e no Brasil, a partir das transformações que permitiram a organização dos Estados modernos e acompanharam a instalação da ordem econômica burguesa. Enfoca-se a maneira como o discurso médico colaborou na promoção de novas formas de relação familiar pelo favorecimento de características específicas para o papel materno, destacando-se a participação tanto da Medicina quanto da Psicologia na instituição das novas configurações que os processos de subjetivação têm assumido na atualidade.

Palavras-Chave: Maternidade, família, modernidade, Psicologia.

Abstract: In this article it is discussed the naturalization of concepts and practices related to maternity and to maternal care, associating their social construction to the modifications family has gone through, in Europe and Brazil, since the transformations that allowed the modern States arrangement and followed the installation of the bourgeois economical order. It is focused the way medical speech collaborated in the promotion of new types of familiar relationship in support of specific characteristics to the maternal function, detaching the partnership of Medicine as well as Psychology in the institution of the new arrangement that the subjective processes have assumed nowadays.

Key Words: Maternity, family, modernity, Psychology.

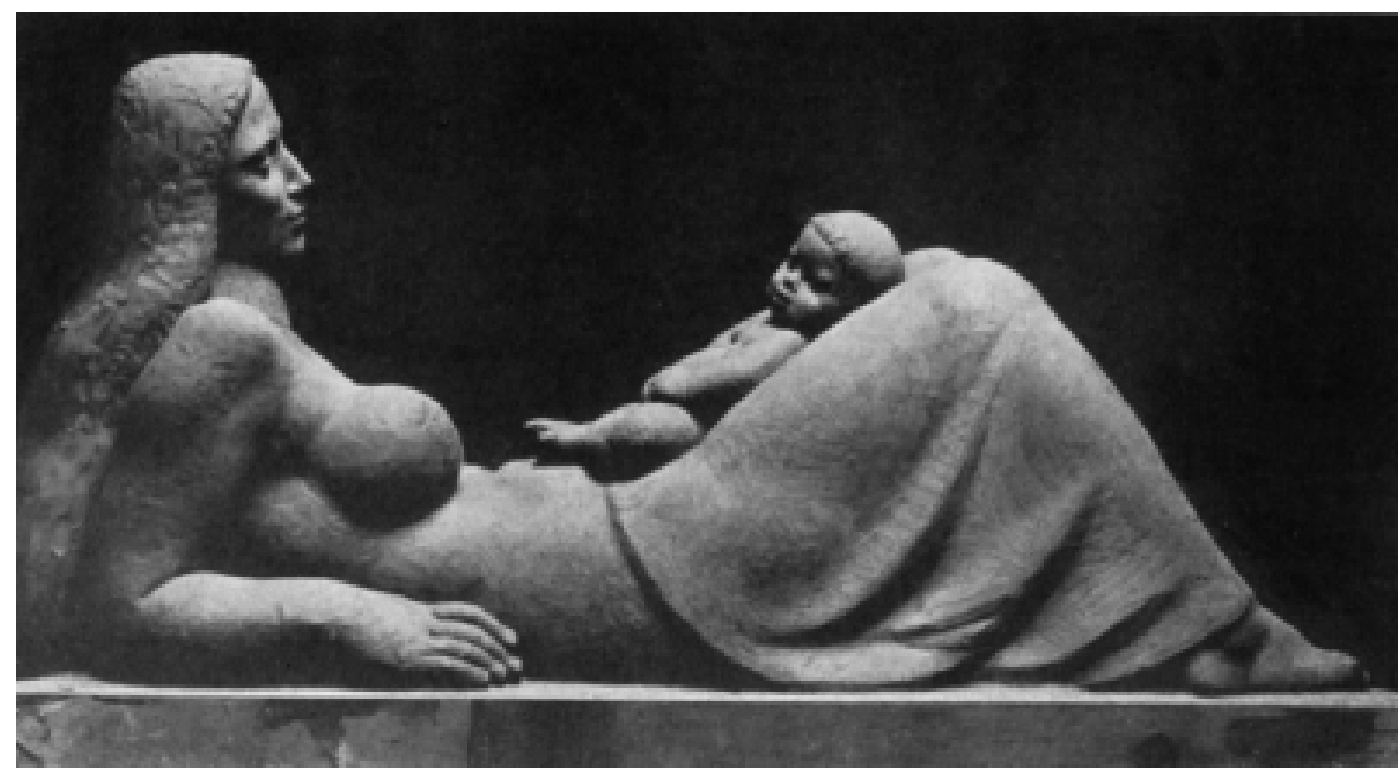

A proposta deste artigo é discutir, a partir de uma revisão bibliográfica, a naturalização de conceitos e práticas relacionadas à maternidade e aos cuidados maternos, associando-se sua construção social às modificações pelas quais a família tem passado na Europa e no Brasil. Essas modificações articulam-se às transformações econômicas que permitiram a organização dos Estados modernos e acompanharam a instalação da ordem econômica burguesa, a partir do século XVII, em um amplo movimento de constituição das chamadas sociedades disciplinares (Deleuze, 1992).
Nesta análise, a maneira como o discurso médico colaborou na promoção de uma nova forma de relação mãe-filhos, pelo favorecimento de características específicas para o papel materno, ocupa lugar central. Enfoca-se, assim, a participação da Medicina e também da Psicologia, em sua aliança com a família, na instituição das novas configurações que os processos de subjetivação têm assumido na atualidade.

A produção da subjetividade é tomada aqui como um processo que determina "a maneira de os 
indivíduos perceberem o mundo e apreenderem sistemas de valores e sistemas de submissão" (Carvalho, 1997), que modela, portanto, seus comportamentos, sua percepção, sua memória, sua sensibilidade e a forma como se relacionam. Parte-se, pois, da idéia de que, historicamente, o valor dado ao relacionamento mãe-criança nem sempre foi o mesmo, sendo que as variações que as concepções e práticas relacionadas à maternagem apresentam são produzidas por uma série de agenciamentos sociais, dentre os quais os discursos e práticas científicas assumem um importante papel.

Durante um longo período, a maternagem foi pensada como intrinsecamente relacionada à maternidade, como função feminina por excelência, concernente à natureza da mulher, embora alguns autores apontem para o fato de que essa dedicação da mulher ao papel materno deva-se muito mais "a uma transposição social e cultural das suas capacidades de dar à luz e amamentar" (Chodorow, 1990). Na verdade, diversas revisões históricas acerca da instituição familiar (Ariés, 1981, Badinter, 1985, Chodorow, 1990, Donzelot, 1986) sugerem que a exaltação ao amor materno é fato relativamente recente dentro da história da civilização ocidental, constituindo-se esse tipo de vínculo, tradicionalmente descrito como "instintivo" e "natural", em um mito construído pelos discursos filosófico, médico e político a partir do século XVIII.

Quando o papel da mulher nessa relação é focalizado, a função biológica da maternidade deve ser, a princípio, distinta daquilo que se convenciona denominar cuidados maternos ou práticas de maternagem. Sobre essas práticas, a cultura nas diversas sociedades tem estabelecido convenções guiadas pela produção dos mais variados campos de conhecimento. É importante também lembrar que o papel materno deve sempre ser considerado de forma relativa e tridimensional, decorrendo daí a impossibilidade de compreender as modificações nele ocorridas sem fazer referência aos demais membros do microssistema familiar (paimãe-filhos).

\section{Da Idade Média ao Renascimento: a transformação das práticas de maternagem na Europa}

Badinter (1985) recuperou a condição de maternagem comum na Europa, especificamente na França, até meados do século XVIII. Em seu trabalho, identificou a desvalorização dada à maternidade em toda a Idade Média e mesmo na Antigüidade como relacionada à ênfase no poder paterno que acompanhava a autoridade marital. O homem era, então, percebido como superior à mulher e à criança, diferença essa concebida como inerente à natureza humana, que o dotaria, pois, de uma autoridade natural sobre a esposa e os filhos.

A constituição da família, portanto, diferia muito, até o século XVIII, das formas de organização encontradas posteriormente e que se tornaram predominantes no período moderno, caracterizadas por sentimentos de ternura e intimidade ligando pais e filhos ou pela valorização da criança. Se o homem ocupava então o lugar central da família, a condição da esposa equiparava-se à da criança, ou seja, era de submissão a sua autoridade. O casamento realizado por contrato, segundo as necessidades econômicas e as alianças políticas das famílias, inibia qualquer expressão de afetividade entre os cônjuges, sendo o amor conjugal considerado desnecessário a um bom casamento. Nesse contexto, a posição ocupada pela criança também diferia daquela experimentada posteriormente.

Ariés (1981), em trabalho no qual discute o desenvolvimento do sentimento de infância na Europa, sugere que seu aparecimento se relaciona às transformações pelas quais a família medieval teria passado até adquirir as características identificadas na modernidade. De acordo com esse autor, na Idade Média as crianças permaneciam vinculadas às suas famílias por pouco tempo, até entre os 07 e 10 anos, quando eram entregues a outras famílias (por contrato ou não) para receberem instrução na condição de aprendizes. A aprendizagem não se exercia na condição formal da escola, mas confundia-se com o exercício das tarefas domésticas cotidianas, sendo o convívio constante com os adultos parte desse processo.

Assim que podia prescindir dos cuidados da mãe ou da ama, a criança passava à condição semelhante à do adulto, misturando-se a eles em todas as atividades sociais. A criança pequena não era tida em conta, o que, de acordo com Ariés (op. cit.) justificava-se em parte pela fragilidade física, que tornava sua sobrevivência pouco provável nas condições da época. Badinter (1985, p. 87), contudo, examinando a justificativa corrente ao desinteresse materno até o século XVIII, qual seja, a elevada mortalidade infantil no período (da ordem de $25 \%$ dos nascidos vivos) que não permitiria à mulher apegar-se a uma criatura com tão poucas possibilidades de sobrevivência, inverte essa afirmativa, questionando se não seria justamente a falta de apego das mulheres a seus filhos que determinaria a alta mortalidade. 
Ariés (1981) informa-nos que, já a partir do século XVII, algumas transformações indicam a emergência de um novo sentimento familiar associado à valorização da infância. Entre elas, podemos citar a modificação dos hábitos educacionais, passando-se da aprendizagem cotidiana exercida no ambiente doméstico à escolarização maciça da infância e a modificação da condição de transmissão de bens, passando-se a reconhecer a igualdade entre os filhos no direito à herança.

"Estudos atuais mostram como a vida coletiva vai dando lugar a um espaço privado de vida. As casas modificam sua arquitetura para reservar aos indivíduos locais privados; os nomes se

individualizam

roupas, guardanapos e lençóis ganham marcas, de modo a permitir sua

identificação. A vida do trabalho sai da casa para a fábrica modificando o

caráter da vida

pública. A casa tornase lugar reservado à família que, em seu interior, divide espaços, de forma a permitir lugares mais individuais e privados"

Bock

1 As tecnologias políticas podem ser entendidas como um conjunto de práticas que investirão sobre o corpo, a saúde, as formas de alimentar e morar, enfim. espaço completo da existência humana.
Essas modificações, porém, instauraram-se lentamente, não sem resistências, de forma que somente no último terço do século XVIII sua disseminação é mais evidente. O foco ideológico desloca-se progressivamente da autoridade paterna ao amor materno, pois a nova ordem econômica que passa a vigorar com a ascensão da burguesia entre outros, a sobrevivência das crianças.

Após 1760, inúmeras publicações passaram a exaltar o "amor materno" como um valor ao mesmo tempo natural e social, favorável à espécie e à sociedade, incentivando a mulher a assumir diretamente os cuidados com a prole. Dessa forma, em defesa da criança dois diferentes discursos confluíram para modificar a atitude da mulher perante os filhos: (1) um discurso econômico, apoiado em estudos demográficos, que demonstrava a importância do numerário populacional para um país e alertava quanto aos perigos (e prejuízos) decorrentes de um suposto declínio populacional em toda a Europa e (2) uma nova filosofia - o liberalismo - que se aliava ao discurso econômico, favorecendo ideais de liberdade, igualdade e felicidade individual (cf. Badinter, 1985).

No campo das relações sociais, assistiu-se, a partir de então, ao desenvolvimento da noção de vida privada.

"Estudos atuais mostram como a vida coletiva vai dando lugar a um espaço privado de vida. As casas modificam sua arquitetura para reservar aos indivíduos locais privados; os nomes se individualizam; roupas, guardanapos e lençóis ganham marcas, de modo a permitir sua identificação. A vida do trabalho sai da casa para a fábrica, modificando o caráter da vida pública. A casa torna-se lugar reservado à família que, em seu interior, divide espaços, de forma a permitir lugares mais individuais e privados" (Bock, 2001, p.19).

A relação conjugal modificou-se, uma vez que o antigo casamento por contrato não era conveniente aos novos ideais libertários e igualitários, passando o casamento por amor para enquanto classe social impunha como imperativo, a ordem do dia. A felicidade conjugal ganhou importância para a família e, ainda que a distinção entre homem e mulher permanecesse, a consciência social modificou-se em relação ao sentido da família e da infância, alterando profundamente as relações marido-esposa e paisfilhos.

Articulando-se aos interesses econômicos do Estado, um outro discurso proferido por médicos, moralistas, administradores e chefes de polícia reforçava a necessidade de a mulher ocupar-se com os filhos. Tal discurso baseava-se, principalmente, no argumento de que essa seria a forma "natural" de cuidados com a criança e, por isso, a mais adequada; uma vez que só a mulher era capaz de gestar e parir, seriam, pois, concernentes apenas à "natureza feminina" a educação e os cuidados com a prole.

Em estudo que denominou "história das mentalidades", Donzelot (1986), baseando-se nos trabalhos de Foucault, identificou nas chamadas tecnologias políticas ${ }^{1}$ os elementos portadores das transformações que se verificaram nas condições de vida na França a partir do século XVIII e também em outros países da Europa.

Em seu trabalho, o autor sugere que, embora o tema do cuidado com as crianças tenha se tornado recorrente na França a partir de meados do século XVIII, nas publicações elaboradas por médicos, administradores e outros que questionavam os hábitos educativos em vigor, essa crítica, porém, não se mostrava homogênea, mas distinta segundo a camada da população a que se dirigia.

De acordo com Donzelot (op. cit.), sobre a camada mais pobre da população incidia uma crítica pela ausência de uma "economia social". A crítica dirigia-se tanto à prática da criação de filhos por amas-de-leite mercenárias quanto ao abandono de menores em hospícios. Ambas as ações tinham como conseqüência uma elevada mortalidade de indivíduos; a última, especialmente, exigia investimentos do Estado dos quais a sociedade extraia mínimo benefício posterior, pois a população carente atendida nos hospícios raramente chegava à idade adulta, quando poderia então compensar os investimentos do poder público através do trabalho. Em outro extremo, a crítica que incidia sobre a camada mais rica da população tinha um foco diferente, nesse caso dirigido à ausência de uma "economia do corpo" . A necessidade de sobrevivência das crianças requeria, também nos segmentos mais abastados da sociedade, a modificação de hábitos antigos, como o recurso ao aleitamento mercenário. Exigia, 
além disso, a alteração da forma como as crianças ricas eram educadas, em geral afastadas da família e reclusas em internatos e conventos até seu ingresso no mundo social adulto.

Em função das diversas críticas, "conservar a criança" significou, segundo Donzelot, (op. cit.) intervir nas famílias e reorganizar os comportamentos educativos em torno de dois pólos, com estratégias diferentes porque dirigidas a classes distintas da população. Nas camadas abastadas, o cuidado com a criança apoiou-se na difusão da medicina doméstica enquanto conjunto de técnicas que permitiram às classes burguesas retirar seus filhos da "influência negativa" dos serviçais, colocando-os sob o domínio dos pais - introduzindo, portanto, na família, uma "economia do corpo", na qual a disciplina, através da vigilância e minucioso controle, ter-se-ia mostrado essencial. Já nas camadas populares, essa intervenção apoiou-se nas estratégias da filantropia que, distinguindo-se das formas de caridade exercidas no antigo regime, englobavam "todas as formas de direção da vida dos pobres com o objetivo de diminuir o custo social de sua reprodução" (Donzelot, 1986,p.22), ou seja, pela introdução de uma "economia social" que compreenderia o desenvolvimento de um extenso e coeso aparato de tutela a essas famílias.

Nos segmentos economicamente mais favorecidos da sociedade, a ligação entre médico e família teria produzido modificações profundas na organização familiar: o fechamento da família sobre si mesma, um controle maior sobre a educação e os hábitos de todos os seus membros, e a aliança entre o médico e a mãe que teria beneficiado a ambos - à mulher, promovendo-a socialmente em função do desempenho adequado de seu papel materno; e ao médico, que teve seu poder reforçado contra as antigas estruturas de tratamento e cuidados leigos, e também contra a disciplina religiosa e as formas tradicionais de educação (internato).

Se nas camadas altas houve a ênfase nos laços afetivos, nas camadas populares esses mesmos laços foram progressivamente desfeitos e substituídos pelas políticas sociais de intervenção. Nesses segmentos, as estratégias de intervenção ter-se-iam voltado muito mais para o "entrave de liberdades", tais como o abandono de crianças (assumido ou não pelos pais), as uniões livres (concubinato) e as ações de mendicância e vagabundagem. Em tais famílias, observou-se um progressivo isolamento, operado pela redução de sua "extensividade com o campo social", ou seja, pela desarticulação de antigas redes de relação e troca de favorecimentos. Uma vez isolada, tornou-se mais fácil ao complexo tutelar controlar a família em seus desvios (Donzelot, 1986, p.47).
Essas estratégias diferenciadas repercutiram em diferentes posicionamentos assumidos pela mulher e pela criança, conforme a classe social a que pertenciam, e seu sucesso permitiu a presença do Estado diante de cada indivíduo através da família, ou seja, a passagem de um governo das famílias para um governo através da família.

Com relação à mulher, especificamente, nota-se que, a partir do século XVIII e principalmente no século XIX, desenhou-se uma nova imagem de sua relação com a maternidade, segundo a qual o bebê e a criança transformam-se nos objetos privilegiados da atenção materna. A devoção e presença vigilantes da mãe surgem como valores essenciais, sem os quais os cuidados necessários à preservação da criança não poderiam mais se dar. A ampliação das responsabilidades maternas fezse acompanhar, portanto, de uma crescente valorização da mulher-mãe, a "rainha do lar", dotada de poder e respeitabilidade desde que não transcendesse o domínio doméstico.

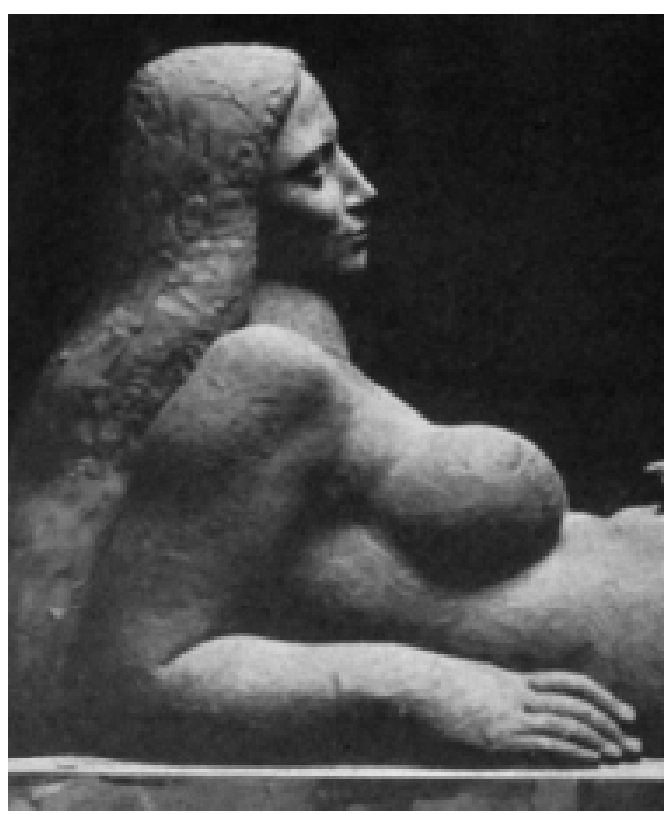

À medida, porém, que as responsabilidades aumentaram, cresceu também a valorização do devotamento e do sacrifício feminino em prol dos filhos e da familia, que novamente surgiram no discurso médico e filosófico como inerentes à natureza da mulher.

Nas classes favorecidas, a mulher passou a assumir, além da função nutrícia, a de educadora e, muitas vezes, a de professora. À medida, porém, que as responsabilidades aumentaram, cresceu também a valorização do devotamento e do sacrifício feminino em prol dos filhos e da família, que novamente surgiram no discurso médico e filosófico como inerentes à natureza da mulher. Assim, se por um lado as novas responsabilidades da mulher conferiam-Ihe um novo status na família e na sociedade, afastar-se delas trazia enorme culpa, além de um novo sentimento de "anormalidade", visto que contrariava a natureza, o que só podia ser explicado como desvio ou patologia. 
Acompanhando essa valorização da maternidade, o papel paterno experimentou, também, a partir do século XVIII, alterações marcadas pelo forte declínio de seu valor. Nas camadas populares da sociedade, a ausência paterna e o descumprimento de suas funções foram progressivamente assumidos pelo Estado através de suas instituições. Nas camadas abastadas, foi o discurso do especialista que acorreu à família oferecendo novo padrão de atitudes.

A esse respeito, Donzelot (1986) considerou que o movimento de isolamento da família em relação à comunidade concorreu para sua progressiva fragilização, especialmente agravada quando a autoridade paterna teve seu poder atenuado diante da valorização da mulher como educadora e aliada do poder médico. Foram então os especialistas no início os médicos higienistas, depois os pedagogos, os psiquiatras e mais tarde os psicólogos e psicanalistas - que, através de suas intervenções, contribuíram para a construção de normativas destinadas a regular a vida familiar e individual, as quais passaram a ser seguidas não mais a partir da imposição ou do receio da punição, mas pelo desejo cultivado e orientado de uma vida normal e saudável.

\section{A Transformação dos Cuidados Maternos no Brasil: do Período Colonial à Constituição do Estado Moderno}

Enquanto na Europa o processo que modificou a intimidade e os sentimentos em relação à vida familiar acompanhou a constituição dos Estados modernos, acentuando-se a partir do período das revoluções liberais, no Brasil o mesmo processo seguiu a passagem do território da condição de colônia a nação. Nesse sentido, compreender as características da vida familiar e dos sentimentos relativos à maternidade naquele período envolve correlações entre a própria estrutura da colonização moderna e as manifestações de intimidade.

De acordo com Algranti (1997), entre os séculos XVI e XVIII, a organização familiar colonial foi marcada pelos mesmos elementos que influenciaram profundamente a formação da sociedade brasileira.

“Nos núcleos urbanos, o que se nota é uma sociabilidade que corre de modo predominantemente fora de casa, pautada por um mundo em que todos se conhecem, e em que se identificam socialmente pelas suas vestes, pelos ofícios. (...) No mundo rural, as grandes distâncias e o isolamento nem sempre favoreceram a intimidade, quer pela presença de muitos escravos nos latifúndios, quer pelo próprio caráter das relações de dominação típicas da sociedade colonial" (Algranti, op. cit., p.152).

No ambiente doméstico, notava-se uma indefinição de espaços privados. No interior da casa, trabalho e convivência familiar sobrepunham-se, e pouca ou nenhuma distinção se fazia no uso dos cômodos. Nas atividades cotidianas, geralmente relacionadas à subsistência, senhor e escravo conviviam lado a lado. Também no cuidado com a criança, nenhuma indicação restou de que lhe fosse reservado um espaço ou uma forma de tratamento que a diferenciasse dos demais membros da família.

Além da dificuldade em delimitar-se uma vida privada nesse período, estudos atuais questionam a existência de uma forma única assumida pela família na colônia, tanto se for considerada toda a extensão temporal do período colonial (mais de três séculos) quanto ao levar-se em conta a diversidade da ocupação do território na mesma época, que se desenvolvia de forma variada conforme a região.

“Tantas foram as formas que a família colonial assumiu, que a historiografia recente tem explorado em detalhe suas origens e o caráter das uniões, enfatizando-lhe a multiplicidade e especificidade em função das características regionais da colonização e da estratificação social dos indivíduos" (Algranti, 1997, p.87).

No Brasil, assim como na Europa, o desenvolvimento da organização e dos sentimentos presentes na família moderna, incluindo aqueles relacionados à maternidade e aos cuidados maternos, foi marcado pelas intensas modificações ocorridas pela ascensão burguesa no final do século XVIII, embora aqui revestidas de características específicas à condição de paíscolônia que se vê subitamente elevado à sede do governo português.

Com a transferência da família real e de toda a corte para o Rio de Janeiro no início do século XIX em conseqüência da instabilidade política vivida pelos regimes absolutistas na Europa, a administração portuguesa desenvolveu um novo tipo de interesse pelas cidades brasileiras. Nesse movimento, promoveu-se uma "reeuropeização" dos costumes coloniais pela transposição, para o Brasil, de hábitos relativos a uma cultura gestada na Europa. Aliados à mulher e à criança, valorizando a "família amorosa", durante o século XIX, os higienistas auxiliaram a família brasileira a assimilar novos valores, nuclearizando-se e urbanizando-se. 
Sob a influência das idéias de Foucault e seguindo o trabalho de Donzelot, Costa (1989) analisou a modificação de costumes e o processo de higienização da família no Brasil, entre os séculos XVIII e XIX, que acompanharam a transformação da família colonial. No movimento de progressiva "estatização" dos indivíduos, produziu-se o que o autor denominou "família colonizada". O processo ter-se-ia dirigido exclusivamente às famílias de extração elitista, não atingindo as camadas menos favorecidas economicamente (que incluíam os escravos), embora o autor reconheça que o modelo familiar dele resultante tenha-se mostrado fortemente hegemônico por um longo período na sociedade brasileira.

Segundo Costa, o novo Estado brasileiro encontrava na família colonial um forte obstáculo à sua consolidação, em razão das características que esta foi adquirindo durante o extenso período subseqüente ao descobrimento até o século XVIII. Tendo-se instalado à distância do governo central, o colono estabeleceu-se como praticamente o único responsável pela ocupação do território; a intervenção da coroa portuguesa apenas ocorria em situações graves, de ameaça ao seu poderio. Nessas condições, "a família 'latifundiária' acumulou uma massa de poder que, em breve, competia com o poder da metrópole" (Costa, op. cit., p.36)

Entre as principais características da família colonial, encontrava-se a valorização do poder paterno. A mulher e os filhos, assim como os demais membros da parentela, interessavam apenas enquanto elementos a serviço do patriarca, e viam na figura do homem não só o protetor, como o patrão, uma vez que a casa colonial funcionava como pequena unidade de produção, dependendo minimamente de outras instâncias para organizar a satisfação de suas necessidades de consumo.

"A higienização das cidades, estratégia do Estado moderno, esbarrava freqüentemente nos hábitos e condutas que repetiam a tradição familiar e levavam os indivíduos a não se subordinarem aos objetivos do governo. A reconversão das famílias ao Estado pela higiene tornou-se uma tarefa urgente dos médicos. (...). No curso do Segundo Império, sobretudo, a medicina social vai dirigirse à família 'burguesa' citadina, procurando modificar a conduta física, intelectual, moral, sexual e social dos seus membros com vistas à sua adaptação ao sistema econômico e político" (Costa,1989, p.30-33).

Segundo o mesmo autor, no Brasil, o processo de "estatização dos indivíduos" teve sobre a mulher um efeito específico: sua redução à figura da "mãe higiênica". Essa nova condição, contudo, só foi possível através da aliança da família com o poder médico. Dessa forma, tanto aqui como na Europa, para a produção da "mãe higiênica", foi fundamental o discurso higienista, no ataque tanto ao aleitamento mercenário (no Brasil realizado por escravas) como responsável pela mortalidade infantil, quanto à suposta deformação moral das crianças pelo cuidado e convivência com amas e lacaios negros.

O comportamento comum na sociedade da época, de recusa ao aleitamento materno. foi codificado também no Brasil pelo discurso higiênico como uma infração às leis da natureza, o que permitiu não somente a culpabilização das infratoras, mas a instalação de um sentimento de anomalia. Além disso, a insistência quanto à amamentação permitiu que se regulasse a vida da mulher, confinando-a por um longo período ao ambiente doméstico (os períodos de aleitamento se estendiam por dois anos ou mais), porém voltando sua atenção ao cuidado, à educação e à vigilância não só da criança como também da família. Também aqui, os cuidados maternos passam a ser valorizados e esse novo olhar sobre a criança possibilitou a manifestação do "amor materno", que tornou-se não somente desejável como "natural". Assim, por todo o século XIX, deu-se a adaptação do modelo de família burguesa européia à sociedade colonial brasileira que, com o auxílio dos médicos higienistas, adquiriu aqui um "colorido tropical".

\section{A Família Contemporânea e a Constituição da "Nova Maternidade"}

Cabe agora refletir acerca das condições de maternagem e das características que o sentimento materno vem assumindo na sociedade contemporânea. O papel da mulher no cuidado com os filhos, segundo Chodorow (1990), tornouse, no último século, tanto mais exclusivo quanto menor se tornava a determinação biológica para a maternidade. Enquanto as taxas de natalidade caíam, a escolarização das crianças tornava-se mais precoce e as mulheres mais presentes no mercado de trabalho, tanto mais crescia a ideologia da "mãe moral".

"Nos Estados Unidos, o período capitalista inicial produziu uma ideologia da 'mãe moral': as mulheres burguesas deviam agir ao mesmo tempo como educadoras e modelos morais para seus filhos, assim como alimentadoras e guias morais para seus maridos na sua volta do mundo de trabalho imoral e competitivo" (Chodorow, op.cit., p.19).
No curso do Segundo Império, sobretudo, a medicina social vai dirigir-se à família 'burguesa' citadina, procurando modificar a conduta física, intelectual, moral, sexual e social dos seus membros com vistas à sua adaptação ao sistema econômico e político"

costa 
A autora indica a psicologia e a sociologia pósfreudianas como importantes fontes dos argumentos que contribuíram para a idealização e o reforço do papel materno, na medida em que enfocaram a relação mãe-bebê como decisiva no desenvolvimento da criança. Com relação a esse aspecto, cabe lembrar que autores como Klein (1986) e Winnicott (1983, 1988a, 1988b, 1993a, 1993b) dedicaram-se exaustivamente ao estudo das chamadas relações objetais primitivas. É fundamental, no trabalho de Winnicott, tanto a valorização do ambiente no desenvolvimento infantil, quanto o delineamento da figura da "mãe dedicada comum", definida como aquela capaz de "promover a integração das características próprias de cada criança, diferenciando cada bebê de outro, a partir do apoio encontrado no ego materno que age como facilitador da organização do próprio ego do bebê" (Winnicott, 1988b, p.494).

2 A cultura psicanalítica pode ser definida como o efeito da difusão da Psicologia e especialmente, da Psicanálise na sociedade, de forma que o cotidiano de um grupo passe a ser compreendido e tematizado por suas normas. A esse respeito, ver: Figueira, S. A Cultura da Psicanálise. São Paulo: Brasiliense, 1985.

3 Comum nas camadas médias urbanas cariocas na década de 80, o "casal grávido" representava uma experiência diferenciada de gravidez compartilhada pelo casal, cujo projeto seria vivenciá-la enquanto unidade nuclearizada e individualizada, ou seja, destacada das redes de parentesco, distinguindo-se da maneira como casais tradicionais o fariam. Esse projeto representaria, assim, uma acentuação do processo de fechamento da família sobre seu próprio núcleo, característico dessa instituição no período moderno.

4 A respeito das modificações observadas nas famúlias de camadas médias urbanas nas últimas décadas do século $X X$ no Brasil, guiadas pelo ideal igualitário, ver: Araújo, M. F. Família Igualitária ou Democrática? As Transformações Atuais da Família no Brasil. Dissertação (Mestrado em Psicologia). Pontifícia Universidade Católica, São Paulo, 1993.

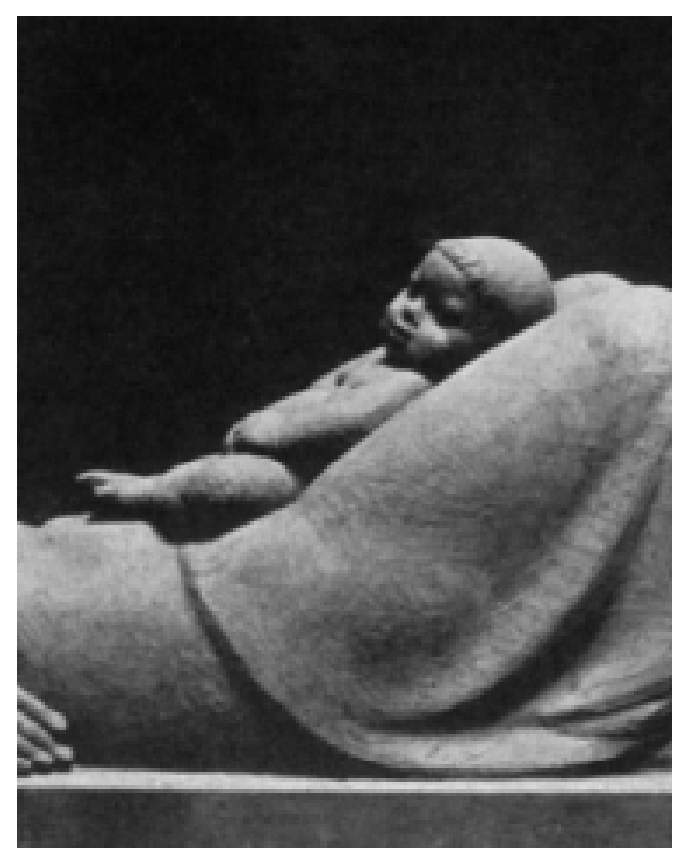

Construído predominantemente em conformidade com uma perspectiva centrada no indivíduo, o discurso psicanalítico passou a ser disseminado amplamente na sociedade contemporânea, muitas vezes de forma pouco crítica. Estudos brasileiros realizados na década de 80 tematizando a família e as modificações ocorridas nos processos de subjetivação (Salem,1985; Lo Bianco,1985; Almeida,1987), associaram tais mudanças às alterações observadas na realidade concreta e apontaram para a influência do discurso da Psicanálise nesse movimento. Essa influência, denominada por alguns autores de "cultura psicanalítica" 2, teria contribuído para que aos papéis materno e paterno fosse acrescida uma perspectiva cada vez mais individualizante.
Salem (1985), entrevistando casais logo após o nascimento do primeiro filho, investigou as modificações na constituição desses papéis em função da maneira como os mesmos casais vivenciavam a gestação, ou seja, na efetivação de um projeto que denominou "casal grávido" ${ }^{3}$.

Segundo a autora, na década de 80 , as representações de maternidade/paternidade deixam de ser percebidas como auto-evidentes e passam a ser vistas como situações sujeitas à elaboração e discussão pelo casal. Esse processo exige forte investimento emocional do homem e da mulher, que devem buscar uma "nova maternidade" e uma "nova paternidade" correspondente. Na referida construção, a valorização do compromisso emocional do casal com a criança intensifica-se, iniciando-se já na gravidez. A participação do pai no parto e nos cuidados com o bebê surge como elemento fundamental dessa experiência. Quanto à mulher, valoriza-se a dedicação total à criança, dispensando-se o auxílio de enfermeiras, babás ou mesmo da família. O casal, portanto, deve assumir todos os cuidados com o bebê, desde o início.

“De um ponto de vista formal, esse arranjo contém um sabor de 'déjà vu': de fato, suas coincidências com a retórica rousseauniana sobre a 'boa mãe' são patentes. Contudo, há uma autoconotação vanguardista reclamada pelos casais grávidos: ela não apenas se ancora na ênfase à participação do homem desde a gravidez como também se afirma a partir do diálogo que estes casais estabelecem com a geração precedente" (Salem, 1985, pp.41-42).

Quanto ao último aspecto, estrutura-se uma nova ideologia educacional que aponta as famílias de origem do casal como modelo negativo, ao mesmo tempo em que se ancora em valores como o afeto, a atenção à subjetividade e a um relacionamento mais igualitário e livre entre pais e filhos. O projeto do "casal grávido", entretanto, só faz sentido dentro do ideário do grupo social a que pertencem esses indivíduos, segundo o qual a própria representação de casal baseia-se na ética da igualdade entre gêneros ${ }^{4}$, "mas está também comprometido com outras ondas ideológicas igualmente significativas, como a recente valorização do subjetivo, do emocional e dos aspectos psicológicos individuais “(Salem, op.cit., p.41).

A autora conclui pela dificuldade da efetivação desse projeto, embora destaque que, na tentativa de sua implementação, sejam significativas as revisões efetivadas pelos casais com relação aos papéis materno e paterno. Aponta também para a importância dos médicos obstetras, psicólogos e outros técnicos envolvidos no acompanhamento 
do casal. Estes, ocupando um lugar que anteriormente era da família extensa, reforçariam a contração da sociabilidade do casal, o que progressivamente demandaria maior dependência dos mesmos especialistas.

No exame dos elementos envolvidos na construção dessa "nova maternidade", Lo Bianco (1985) procurou delinear um de seus aspectos, que denominou "a psicologização do feto" ${ }^{5}$. Tal processo implicaria um tipo de relação com este que anteciparia sua condição de bebê pela atribuição de uma individualidade afetiva. Os procedimentos médicos e de preparação para o parto incrementariam essa ideologia: os registros sonoros e de ultra-sonografias, permitindo a visualização do feto, antecipariam a atribuição de sua identidade, permitindo desde cedo que a mulher identificasse no futuro bebê características próprias, uma personalidade individual.

Em sua análise, a autora inclui o processo no contexto mais amplo das modificações socioculturais que alteraram o papel materno, pela modificação do próprio papel da mulher e da família nas últimas décadas do século XX. Se, nos últimos dois séculos, o papel feminino foi marcado por uma relativa estabilidade e por sua redução ao papel materno, na década de 80, embora essa vinculação não tenha desaparecido, passou a mostrar-se menos estável no contexto de algumas classes sociais, particularmente nas camadas urbanas mais jovens.

De acordo com a autora, já não era mais possível pensar o papel materno como o único disponível para as mulheres, embora permanecesse quase obrigatório e claramente central. Percebia-se, então, "uma ênfase simultânea na importância e obrigatoriedade da maternidade e na importância e possibilidade de desempenho em outros papéis não relacionados ao ser mãe." (Lo Bianco, 1985, p.97). Essa dupla ênfase passou a traduzir-se em uma experiência contraditória e ambivalente em relação ao papel materno. A psicologização do feto teria surgido no contexto dessa ambivalência como tentativa de recriar a experiência materna em novas bases.

Do mesmo modo observado por Salem (1985) nos relatos das experiências de "casais grávidos", para as mulheres entrevistadas por Lo Bianco mostrava-se fundamental preservar o valor da maternidade sem torná-la reprodução da forma como vinha sendo tradicionalmente vivenciada por outras mulheres.

"Há uma ênfase acentuada nesta relação (mãebebê), mas as normas para alcançá-la não são claras. Há, pois, que buscá-las já, desde antes de a maternidade tornar-se uma possibilidade concreta. Assim, a gravidez torna-se tema de escrutínio, e tudo que diz respeito a ela é remetido à ordem dos sentimentos e preocupações para com o feto. Este, por seu turno, é visto como respondendo às atitudes maternas com grande autonomia, isto é, fazendo valer suas supostas características psíquicas. (...) É ainda considerado parceiro de um diálogo e sujeito-objeto de vigilância cuidadosa e detalhada" (Lo Bianco, 1985, pp.110-111).

Embora valorizada e extremamente investida afetivamente, a gravidez não podia tornar-se central e exclusiva na vida das mulheres, o que representaria um retrocesso à forma tradicional de vivenciá-la; o papel feminino deveria conter a maternidade, sem deixar-se englobar por ela. Contrariando tamanha ênfase na gestação e no feto, surgia nas mulheres das classes médias uma freqüente irritação ao verem-se reduzidas ao papel materno, mesmo quando isso ocorria através de gentilezas e concessões à sua condição de gestante. Mesmo o tradicional vestuário de grávida era recusado, tendência que se confirmou posteriormente, até o total desaparecimento de trajes específicos da gravidez. Na década de 90, a exibição da barriga popularizou-se, porém sempre associada a roupas que traduzissem juventude adolescente e um padrão de elegância (ou extravagância) típico de mulheres não-grávidas.

Almeida (1987) também se propôs a discutir a situação da família brasileira no contexto de mudança social e cultural acelerada, buscando captar os elementos que conduziriam à construção desse novo modelo de maternidade ${ }^{6}$, alternativo ao padrão vigente e que a autora denominou "paradigma alternativo".

Em seu trabalho, identifica um processo de nuclearização da família orientado pela ideologia individualista, segundo a qual a experiência de maternidade diria respeito somente ao casal e, em última instância, à vivência pessoal da mulher. $\mathrm{Na}$ década de 80, as mulheres passaram a vivenciar o que a autora denominou "sentimento moderno de maternidade". A família deixou de ser a principal referência na constituição deste modelo, sendo substituída pelo especialista ou por grupos de pares. A diferença desaparece como princípio lógico e exclusivo na organização das experiências sociais e familiares: homem/mulher, pai/mãe, marido/esposa, adulto/criança deixaram de ter seus papéis sociais estabelecidos apenas a partir de diferenças sexuais e de uma estruturação hierárquica.

Na experiência pessoal, a vivência da gravidez não era mais percebida como qualitativamente diversa
5 Através de entrevistas com gestantes de duas classes sociais distintas, procurou identificar a constituição de uma nova relação com o feto, que teria por base a busca do aperfeiçoamento na relação materno-infantil, levando-a a retroceder ao período pré-natal.

6 Procurando identificar tais elementos, entrevistou dois grupos de mães pertencentes a gerações distintas (gestantes dos anos 80 e suas mães, que tiveram os filhos na década de 50), apreendendo, assim, duas experiências distintas de maternidade. 
do período não-grávido, levando ao desaparecimento das distinções quanto à rotina, postura, vestuário. A presença do marido em todos os momentos da gestação passou a ser valorizada. A gestação, para essas mulheres, passava a ser percebida como escolha pessoal, devendo ser problematizados todos os aspectos relacionados à sua evolução.

Almeida (op. cit.) também destaca a relação estabelecida pelas mulheres nos anos 1980 com o que chamou de "profissionais da gravidez". Se, anteriormente, o acompanhamento da gestação restringia-se ao obstetra, uma série de outros profissionais inseriu-se nesse processo: na época, passaram a estar presentes especialistas em Psicologia e em trabalhos de corpo aplicados à gravidez e ao parto. Esses profissionais tornaram-se responsáveis, junto às mães, pela construção e divulgação de um "paradigma alternativo" na concepção de maternidade.

Na visão da autora, o novo paradigma mostrava-se essencialmente reativo aos antigos valores e crenças, que passaram a ser atacados e atingidos basicamente através de seus representantes - a família de origem, a ideologia médica tradicional, mas também outras gestantes contemporâneas que não se filiavam ao novo modelo. Uma postura de afastamento e crítica (superficial) era favorecida, especialmente através dos profissionais "psi" que, junto aos grupos de pares, passavam a ser tomados como sede de estabelecimento de novos valores, supostamente porque incentivariam a emergência de um desejo individual em relação à maternidade.

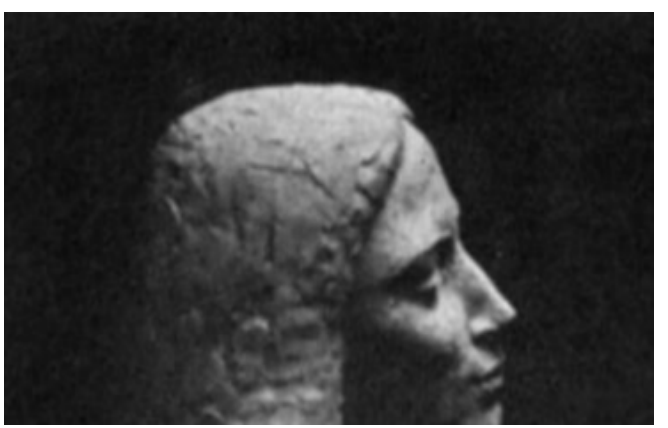

Para Almeida (1987), essa atitude dos especialistas conteria, na verdade, um padrão disciplinador sutil. A ideologia alternativa não seria, contudo, percebida como tal, confundindo-se com a crença na aquisição de modalidades de liberação frente a condutas e valores antigos. Tais relações estariam compreendidas, portanto, em um campo rigorosamente disciplinar; sua "novidade" estaria no fato de essas estratégias de controle e convencimento serem percebidas como concernentes ao desejo do próprio sujeito, o que favoreceria grandemente a adesão às normativas.

Se, na década de 80, os efeitos de uma progressiva individualização e "psicologização" das relações na sociedade se fizeram sentir de maneira mais aguda nas camadas urbanas da população, intelectualizadas e familiarizadas com o universo de valores da classe média, nos últimos anos, a participação de profissionais "psi" em trabalhos dirigidos a outras camadas sociais acentuou-se. $\mathrm{O}$ aumento dessa participação deu-se, em parte, em função do empobrecimento geral da população durante os anos críticos da década de 90, obrigando esses profissionais a dirigirem-se a outros campos de trabalho além do consultório particular. Ocorreu também a partir do crescimento assombroso no número de profissionais das áreas "psi" no mercado, em função do fenômeno conhecido como "boom da Psicanálise" nas décadas anteriores.Esse momento trouxe, entre outras coisas, um aumento na procura por cursos de formação em Psicologia e por instituições de formação de psicanalistas ou terapeutas de orientação analítica.

A penetração dessa forma de discurso favorecia e era favorecida pela ordem econômica vigente. A presença de profissionais "psi" nos meios de comunicação de massa tornou-se cada vez mais freqüente, veiculando conselhos e orientações através de jornais, de revistas e da televisão. Suas abordagens, muitas vezes conferindo grande valor aos aspectos subjetivos das relações e ao desenvolvimento da individualidade, estimularam um aporte individual para questões nas quais o contexto socioeconômico e político do País mostrava-se fortemente implicado. O mesmo tipo de abordagem permitia ainda a generalização de alternativas específicas a um determinado contexto populacional para toda a sociedade.

Além disso, a partir do final da década de 1970 um amplo movimento mundial no campo da saúde modificou a maneira como os serviços de atenção à população se organizavam, propondo a revisão do próprio conceito de saúde ${ }^{7}$. O advento do chamado "paradigma biopsicossocial", preconizando um novo tipo de intervenção através das equipes multiprofissionais, levou um grande número de psicólogos a atuações relacionadas aos setores básicos (chamados primários e secundários), ampliando intervenções antes dirigidas somente às instituições psiquiátricas para atingir as unidades básicas de saúde, os ambulatórios e hospitais gerais. A Psicologia, acompanhando a Medicina, passou a ter lugar em inúmeros programas de saúde pública, colaborando na organização de novas (novas?) formas de cuidado dispensado aos indivíduos. 
Em outro extremo, o progresso científico proporcionado pela Medicina e pela tecnologia de ponta nas últimas décadas, aliado às transformações do papel da mulher na sociedade (evidenciadas especialmente a partir do movimento feminista), tem trazido novas e importantes questões para a família que certamente repercutirão em novas possibilidades de configuração subjetiva. A mulher, depois de conquistar a liberdade de exercer sua sexualidade desvinculada do matrimônio, de planejar e decidir a maternidade, de adiá-la até o momento que considera propício às circunstâncias de sua vida, de interromper uma gestação por meios seguros (embora ilegais no Brasil), pode também optar por viver a maternidade sozinha, sem que isso signifique uma condenação social. Porém, mais que assumir a maternidade fora da condição do casamento, hoje a mulher pode tornar-se mãe sem depender da presença concreta de um companheiro, podendo fazê-lo amparada pelos avanços das técnicas de fertilização assistida. Essas novas tecnologias reprodutivas permitem a gestação em condições anteriormente impensáveis, tanto do ponto de vista médico quanto social. Aliadas a esses avanços, as técnicas de cuidados a recémnascidos que reduzem drasticamente a mortalidade de crianças, mesmo quando nascidas muito prematuras ou gravemente doentes, certamente repercutirão na organização familiar e nos sentimentos relacionados à maternidade.

Correia (1998), em um artigo em que reflete a respeito das novas tecnologias reprodutivas (NTRs), como a inseminação artificial, a fertilização in vitro e suas diversas variantes, incluindo doações de células reprodutivas (óvulos e espermatozóides) e de embriões, aluguel ou empréstimo de útero, até a possibilidade de clonagem humana, considera que "as NTRs constituem a etapa mais recente de um processo cujas origens remontam ao fim do século XVIII, pelo qual, historicamente, a função de cura da Medicina duplica-se em uma outra função, política, de criação e transmissão de normas." (Correia, op. cit., pp.132-133). Sob esse ponto de vista, uma tecnologia de ponta, quando dirigida a aspectos tão permeados de significação quanto à produção e a manutenção da vida humana, pode assumir um caráter não tão moderno assim mas que, lembrando as antigas práticas higienistas, reforça "o velho papel da Medicina na construção de significados em torno da maternidade e da paternidade" (Correia, op. cit., p.132).

Será mais uma vez o discurso do especialista a auxiliar a família diante das novas alternativas de relação e de constituição subjetivas, que se inserem no campo do imaginário antes mesmo de se tornarem uma possibilidade concreta para a sociedade. Ao psicólogo certamente caberá algum papel, uma vez que são justamente os processos de subjetivação o terreno privilegiado de seu trabalho. O exercício de sua função de forma crítica e reflexiva quanto aos fundamentos e conseqüências desses processos mostra-se essencial, sob pena de que seu discurso se reduza, como outros tantos, ao discurso da competência, tal como definido por Chauí (1982).

Para essa autora, o "discurso competente" é o discurso instituído, cuja finalidade seria dissimular, sob uma capa de cientificidade, um trabalho ideológico de identificação de todos os sujeitos sociais com uma imagem particular e universalizante. A condição essencial para o prestígio e a eficácia do discurso da competência consiste na afirmação da incompetência dos homens como sujeitos políticos e sociais válidos, ou seja, para sua disseminação, é preciso que haja apenas homens reduzidos à condição de objetos sociais.

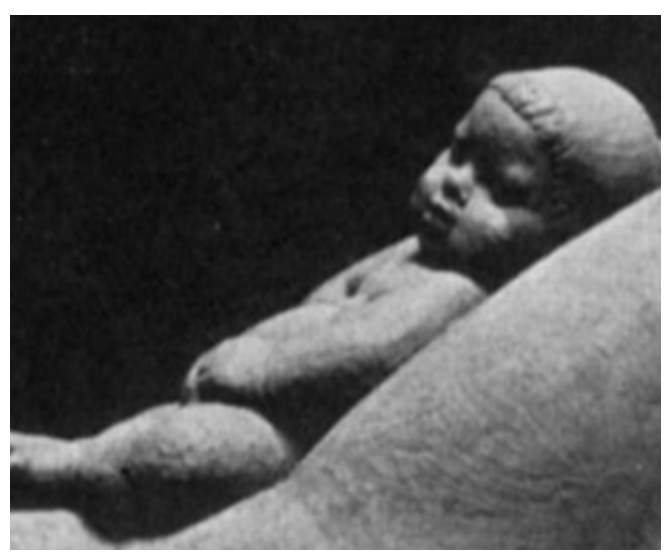

O discurso competente realiza, assim, um duplo movimento: ao mesmo tempo em que afirma a incompetência dos homens, entra em cena para devolver-lhes alguma competência, cientificamente embasada, porém realizada de forma individualizante. "Invalidados como seres sociais e políticos, os homens seriam revalidados por intermédio de uma competência que lhes diz respeito enquanto sujeitos individuais ou pessoas privadas" (Chauí, op. cit., p.12).

A competência lhes é devolvida, portanto, na forma de uma série de discursos que ensinarão a cada um como lidar com o mundo e como se relacionar com o outro. Longe de promover um saber verdadeiro, uma reflexão autêntica sobre si mesmo e a realidade, os discursos da competência divulgam conhecimentos, ao mesmo tempo em que apagam diferenças, anulam as contradições e fazem desaparecer o novo, o diverso. Na verdade, 
para o discurso competente (como discurso ideológico), o "novo" só interessa quando perde seu poder instituinte, tornando-se inócuo, infértil.

As novas questões trazidas à família na contemporaneidade, especialmente no que diz respeito às concepções acerca da maternidade das quais trata este artigo, podem tornar-se elementos instituintes, disparadores de novos processos de subjetivação que, nas palavras de Deleuze (1992, p.217), "só valem na medida em que, quando acontecem, escapam tanto aos saberes constituídos como aos poderes dominantes". Essas mesmas questões podem, no entanto, ser capturadas pelo intenso processo de modelação, de instituição de valores, que tem no especialista um importante elemento para sua efetivação. O lugar do especialista não é, porém, uma determinação: podemos posicionar-nos de outro modo, fazendo de nosso trabalho uma oportunidade de criação e de ruptura com o instituído, um espaço de sua permanente desconstrução.

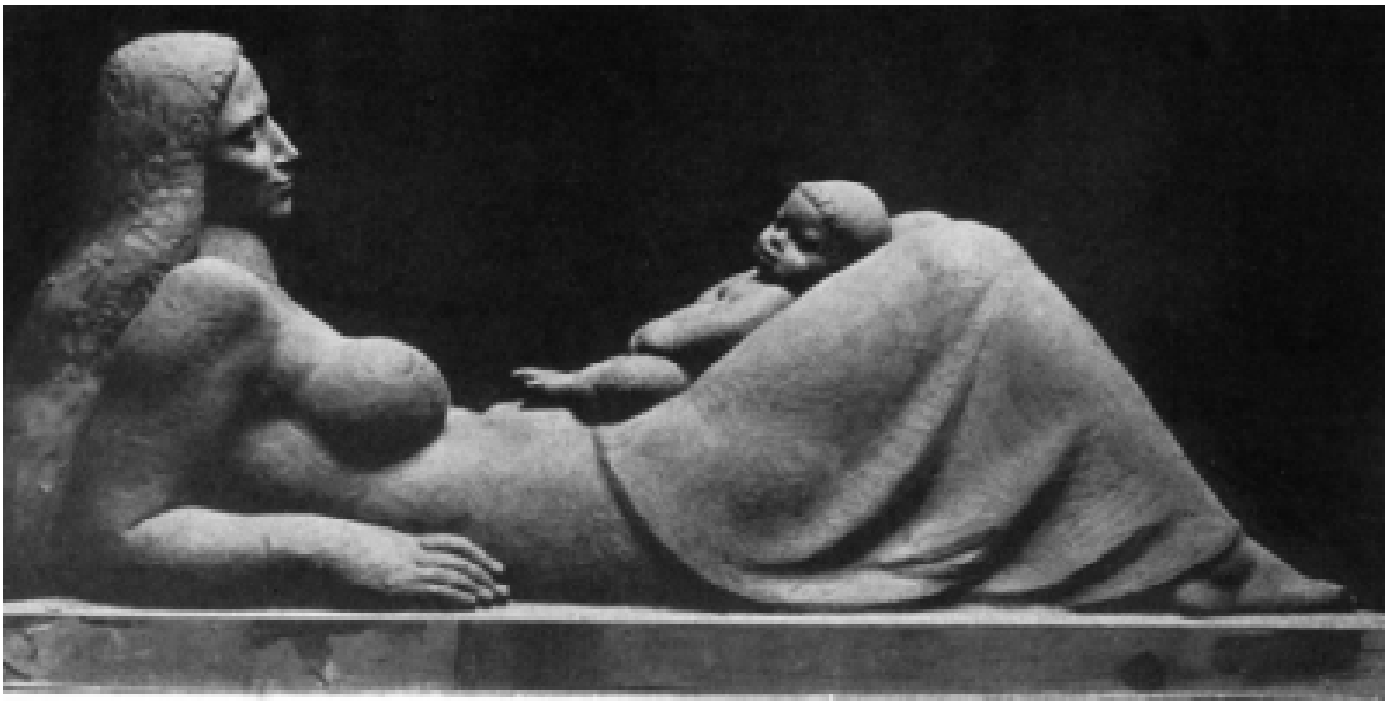


Solange Maria Sobottka Rolim de Moura Rua Julio Prestes, 1380 Centro - Presidente Prudente - SP CEP 19015-210 Email:solrolim@hotmail.com

Maria de Fátima Araújo Departamento de Psicologia Clínica - UNESP Av. Dom Antônio, 2100 Parque Universitário - Assis - SPCEP 19800-000 Email:fatimaraujo@uol.com.br

ALGRANTHI, L. M. Famílias e Vida Doméstica. In Novais, F. A. (coordenador-geral); Mello e Souza, L. (org.). História da Vida Privada no Brasil: Cotidiano e Vida Privada na América Portuguesa. Vol. I. São Paulo: Companhia das Letras, 1997, pp. 84-154.

ALMEIDA, M. I. Maternidade: um Destino Inevitável? Rio de Janeiro: Campus, 1987.

ARIÉS, P. História Social da Criança e da Família. Rio de Janeiro: LTC, 1981.

BADINTER, E. Um Amor Conquistado: o Mito do Amor Materno. Rio de Janeiro: Nova Fronteira, 1985.

BOCK, A. M. B. A Psicologia Sócio-histórica: uma Perspectiva Crítica em Psicologia. In Bock, A. M. B., Marchina, M. G., Furtado, O. (orgs.) Psicologia Sócio-histórica: Uma Perspectiva Crítica em Psicologia. São Paulo: Cortez, 2001, pp.15-35.

CARVALHO, D. R. Cartografando Subjetividades no Brasil. Revista Subjetividades Contemporâneas, São Paulo, v.1, no1, 1997, pp.28-33.

CHAUÍ, M. Cultura e Democracia. O Discurso Competente e Outras Falas. São Paulo: Moderna, 1982

CHODOROW, N. Psicanálise da Maternidade.Uma Crítica a Freud a Partir da Mulher. Rio de Janeiro: Rosa dos Tempos, 1990.

CORREIA, M. V. Novas Tecnologias Reprodutivas: Bem-vindas Reflexões Feministas. Revista Estudos Feministas, São Paulo, v. 6, no 1 , 1998, pp.126-137.
COSTA, J. F. Ordem Médica e Norma Familiar. Rio de Janeiro: Graal, 1987.

DELEUZE, G. Conversações. São Paulo: Editora 34, 1992.

DONZELOT, J. Polícia das Famílias. Rio de Janeiro: Graal, 1986.

KLEIN, M. Os Progressos da Psicanálise. Rio de Janeiro: Guanabara, 1986.

LO BIANCO, A. C. A Psicologização do Feto. In Figueira, S. (org.) A Cultura da Psicanálise. São Paulo: Brasiliense, 1985, pp. 94-115.

SALEM, T. A Trajetória do "Casal Grávido": de sua Constituição à Revisão de seu Projeto. In Figueira, S. (org.) A Cultura da Psicanálise. São Paulo: Brasiliense, 1985, pp. 35-61.

WINNICOT, D.W. O Ambiente e os Processos de Maturação: Estudos Sobre a Teoria do Desenvolvimento Emocional. Porto Alegre: Artes Médicas, 1983.

. Os Bebês e Suas Mães. São Paulo: Martins Fontes, 1988a.

. Textos Selecionados: da Pediatria à Psicanálise. Rio de Janeiro: Francisco Alves, $1988 \mathrm{~b}$

A Família e o Desenvolvimento Individual. São Paulo: Martins $\overline{\text { Fontes, }}$ 1993a.

Conversando com os Pais. São Paulo: Martins Fontes, 1993b. 